\title{
Research on the Announcement Effects of the Convertible Bonds in the A-Share Market of China
}

\author{
Baoqian Wang, Jing Miao, Fengxian Wang \\ School of Business, Hohai University, Nanjing, China \\ Email: wangbaoqian@gmail.com
}

Received 5 March 2014; revised 30 March 2014; accepted 8 April 2014

Copyright (C) 2014 by authors and Scientific Research Publishing Inc.

This work is licensed under the Creative Commons Attribution International License (CC BY).

http://creativecommons.org/licenses/by/4.0/

(c) (i) Open Access

\begin{abstract}
This paper studies the announcement effects of the convertible bonds of 50 listed companies in the A-share market of China. The result shows that there are significant negative effects when the convertible bonds are issued, in other words, issuing announcement of the convertible bonds can lead stock prices to decline. However, the significances of the negative effects are different in different markets, bond types, released years and time windows. The volatility of share prices in Shanghai Stock Exchange is less than in Shenzhen Stock Exchange, and the negative effects are more significant than in SZSE. The announcement effect of the ordinary convertible bonds is more significant than the convertible bonds with warrants.
\end{abstract}

\section{Keywords}

Convertible Bond, Announcement Effect, Event Study, Abnormal Return

\section{Domestic and Foreign Research Summary}

The convertible bond is a kind of bond that allows the holders to convert the bonds into company stocks according to the terms formulated in advance within the stipulated time. Generally, the coupon rate is lower than the common bonds. The convertible bonds belong to the debt capital before the conversion, and then belong to the equity capital after the conversion. Announcement effect is that the announcement of issuing the convertible bonds affects the stock price of the company, and the effects include the volatility size and direction of the stock price. There are a lot of studies about the issuance of new shares and the allotment in China, but the articles that study the announcement effect of the convertible bonds are fewer and the conclusions are inconsistent. Therefore, this paper will study if the announcement information of issuing the convertible bonds in the A-share market can affect the stock price, and we will calculate the specific value of the effect. The research results of the 
announcement effects of the convertible bonds are abundant, and the scholars make a lot of progress. In general, the announcement effects consist of the positive effect and the negative effect in foreign. The effects are negative in the securities markets of the United States, Britain and France; it means that the issue of the convertible bonds would result in a decline in the company's stock price. In particular, the effect is the most obvious in United States, and the value of the average abnormal return rate is about $-2 \%$ [1]. But the effects are positive in the securities markets of Japan and the Netherlands; it means that the issue of the convertible bonds would make the company stock price decline. The value of the average abnormal return rate is about 1.05\% in Japan [2] and the value is about $0.23 \%$ which is relatively smaller [3].

Guo Xinwei [4] is the first person who researches the announcement effects of the convertible bonds in China. He selected 39 companies that issued the convertible bonds before August 31, 2001 as samples, and referenced to the broader market. The study showed that the prices of $60 \%$ of the sample companies declined the days on which the companies released the information about issuing the convertible bonds. And there were $70 \%$ of the companies of which the stock price fell below the market, and the decreases are about 4.6 times higher than the usual decreases of the broader market. Later, many researchers have come to similar result that there are negative effects of the convertible bonds announcement. However, Wang Hui-Yu and Xia Xin-Ping [5] collected 20 companies which issued the convertible bonds to study the announcement effects. The results show that the information of issuance will make the company's stock price increase, and the value of the Cumulative abnormal return rate is $0.26 \%$ on Day 0 . It means that the announcement results in a significant positive effect. Wang Yin-Xiang et al. [6] found that the stock prices would decrease on the day of announcing to issue the convertible bonds, but the positive effect of the announcement gradually reflects in future transactions causing the stock prices to rise. Tian Ke and Lao Lan-Jun [7] selected 23 companies that issued the convertible bonds before April 30, 2004 as the research objects. The results showed that announcement effects of the listed companies of China issuing the convertible bonds are not significant.

Due to the facts that the studies are out of date, the samples are generally fewer and the results are uncertain, this paper selects 50 companies that issued the convertible bonds from January 23, 2007 to March 21, 2012 as the sample data and adopts the Event Study to research the announcement effects of the convertible bonds in the A-share market after the split share structure reform.

\section{Data Selection and Research Method}

\subsection{Data Selection}

In order to improve the effectiveness of securities data, this paper selects the companies as the research objects that issued the convertible bonds after 2007. There are 54 companies which issued the convertible bonds from January 23, 2007 to March 21, 2012. The RZG is excluded due to incomplete data. And the GDDL is excluded due to the instability of the data. So this paper adopts 52 companies as samples and arranges the data simply. All of 52 companies are the listed companies in the territory, including 41 companies (Two companies are excluded In order to ensure the consistency of the overall sample) listed in the SSE and 13 companies listed in the SZSE. The proportion of the manufacturing sector is the largest in the listed companies which issue the convertible bonds. The others belong to transportation and warehousing industry and so on.

\subsection{Event Study and Define the Event Window}

\subsubsection{Event Study}

The Event Study is a method of calculating the size of the impact of an economic event on the value of the company by dealing with the financial data. This paper studies the direction and degree of the effects of the announcement of the convertible bonds, and this research is based on the basis of three implicit assumptions: 1) The capital market is efficient; 2) The event is not expected; 3) There are no other events during the event period. The specific approach is choosing a time interval before and after the event and calculating the rate of the abnormal return when the information of issuing the convertible bonds is announced. In other words, our purpose is testing whether the rate of the abnormal return is significantly different from zero in the study range.

\subsubsection{Define the Event Window}

We choose the day of announcing to issue the convertible bonds as the base date. There are 41 days in the event 
period from the 20th day before the base date to the 20th day after the base date. And we select the data of the samples in 365 days to estimate the expected rate of return. The time window consists of respective20 trading days before and after the base date, in which $-t$ means the th trading day before the base date and $+t$ means the tth trading day after the base day. The event period of the sub-sample includes 20 days $(-10,+10), 10$ days $(-5$, $+5)$, 2 days $(-1,+1)$ and 1 days.

We calculate the rate of return with the market model method, and the formula is as follows:

$$
R_{i, t}=\alpha_{i}+\beta_{i} R_{m, t}+\varepsilon_{i, t}
$$

There $A R_{i, t}$ is the rate of return of Companies i on the tth day, $R_{m, t}$ is the rate of return of the market on the th day, $\varepsilon_{i, t}$ is the error term and $\varepsilon_{i, t} \sim N\left(0, \sigma^{2}\right)$.

The formula of the rate of abnormal return (AR) is as follows: $A R_{i, t}=R_{i, t}-\hat{\alpha}_{i}-\hat{\beta}_{i} R_{m, t}$, and there $A R_{i, t}$ is the AR of Companies i on the th day, $\hat{\alpha}$ and $\hat{\beta}$ is coefficients of OLS in the event period.

The formula of the average rate of the abnormal return (AAR) is as follows: $A A R_{t}=\frac{\sum_{i=1}^{n} A R_{i, t}}{n}$, and there $A A R_{t}$ is the AAR of Companies $i$ on the th day, $\mathrm{n}$ is the number of companies in the samples.

The formula of the cumulative average rate of the abnormal return (CAAR) is as follows:

$$
C A A R_{\left(t_{1}, t_{2}\right)}=\sum_{t=t_{1}}^{t_{2}} A A R_{t}=\frac{1}{n} \sum_{i=1}^{n} \sum_{t=t_{1}}^{t=t_{2}} A R_{i, t},
$$

and $\operatorname{CAAR}_{\left(t_{1}, t_{2}\right)}$ is the CAAR of the samples from $\mathrm{t} 1$ to $\mathrm{t} 2$.

\section{Regression Analysis of the Announcement Effects of the Convertible Bonds}

\subsection{Analysis of the Announcement Effects of the Convertible Bonds of the Overall Samples}

We select respective 20 days before and after the announcement date as the announcement range in order to verify if the rate of the abnormal return is significantly different from zero before and after the announcement date. The AAR and T-statistics are shown in Table 1. The results show that the number of days with a positive rate of abnormal return is more than the number of days with a negative one during the 20 days before the base date and it is opposite during the 20 days after the base date. The most values of the of the AAR are negative after the day before the base date and significant in the confidence interval of $1 \%$, but the value is positive on the day after the base date because of the of random events. The value of the AAR is $-0.46831 \%$ on the6th day after the base date. The value of $\mathrm{T}$ is -1.504 and it is significant in the confidence interval of $5 \%$.

As shown in Figure 1, the value of the CAAR has been rising in the first 17 days of the time interval, and the value $(4.8257 \%)$ reaches a maximum on the day before the base date. The value declines rapidly in the time window $(-1,+3)$. And the value is $-0.458 \%$ on the third day after the base date. The value is negative and relatively stable in the rest 17 days. It is worth noting that the value is always positive when it is increasing. The reason for this result may be the listed companies will take into account the interests of the majority of the tradable shareholders when they issue the convertible bonds. So they will choose the right time to release the issue announcements. In general the right time refers to when the return of the company's stock is significantly higher than the average market income.

The stock prices of the listed companies will decline during the announcement periods. The announcements of the convertible bonds have a negative impact on the market value of the companies in the short-term. The result is consistent with these gotten in the securities markets of the United States, Britain, France and other developed countries. Theory of Information Asymmetry points out that the companies with good operation will choose issuing the bonds to raise funds, the companies with poor operation will choose issuing the stocks, and the ones in between will choose issuing the convertible bonds. In addition, some investors believe that the capital structure can be optimized and the finance costs can be reduced when the companies issue the convertible bonds. Generally speaking, the messages of issuing the convertible bonds are bad news rather than good news for the investors. The stock prices of the companies decline. The rates of the average abnormal return are significantly negative during several days after the base date. 
B. Q. Wang et al.

Table 1. The AAR of the overall samples and T-test.

\begin{tabular}{|c|c|c|c|c|c|c|c|}
\hline Time & AAR & T value & $\mathrm{P}$ value & Time & AAR & T value & $\mathrm{P}$ value \\
\hline-20 & $0.73210 \%$ & 1.783 & 0.123 & 1 & $0.10175 \%$ & 0.119 & 0.780 \\
\hline-19 & $0.90067 \%$ & 2.305 & 0.024 & 2 & $-1.46691 \%$ & $-3.100 * * *$ & 0.003 \\
\hline-18 & $0.40793 \%$ & 1.343 & 0.255 & 3 & $-0.89722 \%$ & $-2.290 * * *$ & 0.022 \\
\hline-17 & $0.66114 \%$ & 1.603 & 0.086 & 4 & $0.13731 \%$ & 0.447 & 0.719 \\
\hline-16 & $0.11737 \%$ & 0.261 & 0.697 & 5 & $0.00676 \%$ & 0.116 & 0.986 \\
\hline-15 & $0.14422 \%$ & 0.315 & 0.691 & 6 & $-0.46831 \%$ & $-1.504^{* *}$ & 0.153 \\
\hline-14 & $-0.02965 \%$ & -0.185 & 0.935 & 7 & $-0.33642 \%$ & -1.148 & 0.294 \\
\hline-13 & $0.12162 \%$ & 0.170 & 0.754 & 8 & $0.08988 \%$ & 0.421 & 0.798 \\
\hline-12 & $0.51776 \%$ & 1.261 & 0.203 & 9 & $-0.18497 \%$ & -0.723 & 0.485 \\
\hline-11 & $0.31245 \%$ & 1.063 & 0.292 & 10 & $-0.20407 \%$ & -0.631 & 0.483 \\
\hline-10 & $0.09090 \%$ & 0.390 & 0.801 & 11 & $-0.09888 \%$ & -0.233 & 0.791 \\
\hline-9 & $-0.22758 \%$ & -0.592 & 0.442 & 12 & $0.12862 \%$ & 0.395 & 0.678 \\
\hline-8 & $-0.38341 \%$ & -0.449 & 0.375 & 13 & $0.31722 \%$ & 0.730 & 0.481 \\
\hline-7 & $0.12495 \%$ & 0.284 & 0.706 & 14 & $-0.21467 \%$ & -0.612 & 0.545 \\
\hline-6 & $-0.12722 \%$ & -0.241 & 0.767 & 15 & $-0.04568 \%$ & -0.069 & 0.888 \\
\hline-5 & $0.54816 \%$ & 1.613 & 0.109 & 16 & $0.41091 \%$ & 1.121 & 0.286 \\
\hline-4 & $0.12457 \%$ & 0.548 & 0.687 & 17 & $-0.22702 \%$ & -0.552 & 0.490 \\
\hline-3 & $0.14057 \%$ & 0.636 & 0.646 & 18 & $-0.28871 \%$ & -0.923 & 0.365 \\
\hline-2 & $0.64918 \%$ & 1.442 & 0.151 & 19 & $-0.01643 \%$ & -0.030 & 0.971 \\
\hline-1 & $-1.14816 \%$ & $-2.716^{* * *}$ & 0.008 & 20 & $-0.04623 \%$ & 0.029 & 0.905 \\
\hline 0 & $-1.87331 \%$ & $-3.667 * * *$ & 0.001 & & & & \\
\hline
\end{tabular}

Note: ***indicates it is significant in the confidence interval of $1 \%, * *$ indicates it is significant in the confidence interval of $5 \%$, and $*$ indicates it is significant in the confidence interval of $10 \%$.

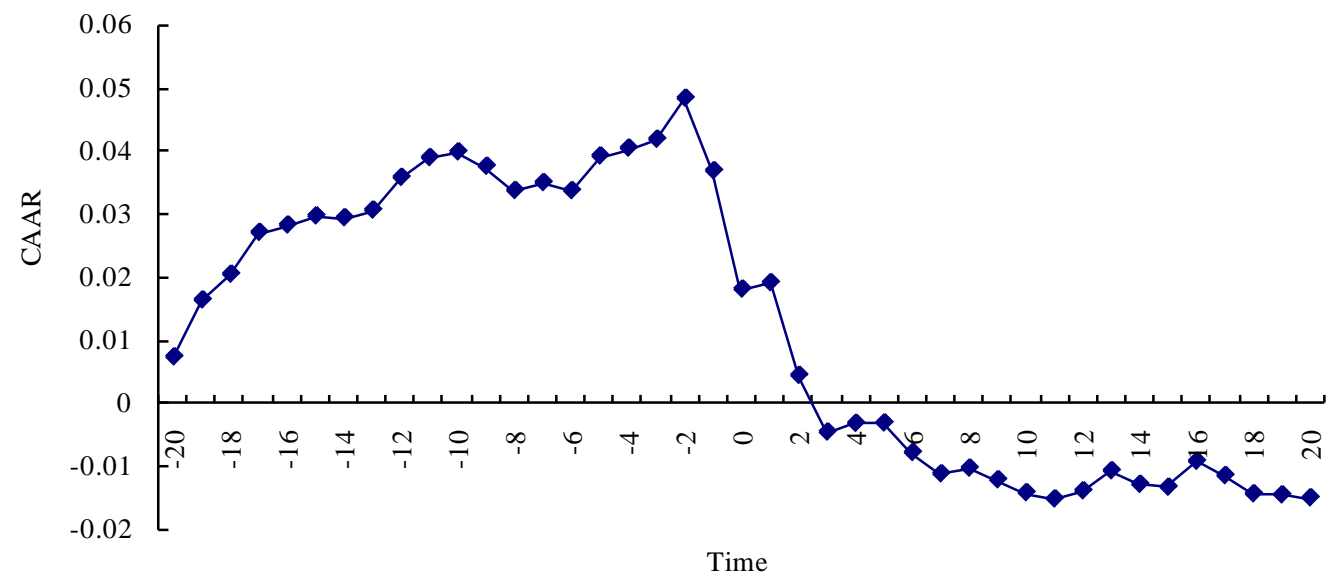

Figure 1. Distribution of the CAAR. 


\subsection{Group Study of the Announcement Effects of the Convertible Bonds}

\subsubsection{Grouped According to the Different Issuance Markets}

There are two issuance markets including the SSE and the SZSE in this paper. As shown in Figure 2, the fluctuation of the values of the average abnormal returns in the SSE is smaller than the one in the SZSE. The number of days with a positive rate of abnormal return is more than the number of days with a negative one during the 10 days before the base date, but it is opposite during the 10 days after the base date. Especially the values are all negative in the time window $(-1,+3)$.The values are negative in several days before the base date in the SZSE, but there are many large fluctuations. So we cannot conclude that there are significant negative effects. And there are only two negative values of Day +2 and Day +7 that pass the test of significance. The cumulative average rates of the abnormal return in two issuance markets are different, too. The positive values of CAAR turn into the negative ones with the passage of the time during the event range. It is more clearly that there are negative announcement effects when issuing the convertible bonds. But the values are always positive during the event range, so we cannot infer if the announcement could affect the rate of return.

Generally speaking, the negative announcement effects are more obvious in SSE than in SZSE. It indicates that the investors in SSE are more sensitive than these in SZSE. There may be many reasons such as the number of samples is relatively small in SZSE resulting in the errors, the announcement effects appear in the market with the interference of the random factors and the securities market in China is not developed enough so that the announcement effects are shown in the market immediately.

\subsubsection{Grouped According to the Different types of the Convertible Bonds}

We select two kinds of convertible bonds including the ordinary convertible bonds and the convertible bonds with warrants in the paper. The convertible bonds with warrants are the convertible bonds that allow the warrants can be traded separately. The Warrants are the right certificates that allow the holders can buy the underlying bonds in accordance with the prices agreed in advance within a certain period of time. So the convertible bonds with warrants are innovative financial products that allow us getting the warrants at the same time while buying the convertible bonds. The convertible bonds with warrants are different from the ordinary convertible bonds in the forms of existence, the duration ,the conditions of issue, the terms of design and so on.

There are 13 companies which issue the convertible bonds with warrants and 37 companies which issue the ordinary convertible bonds in the 50 samples. As shown in Figure 3, there are more fluctuations in the rate of return of the convertible bonds with warrants than the ordinary convertible bonds. The number of the days with the positive abnormal return is larger than the ones with negative return in the samples of the convertible bonds with warrants during the event period, but it is opposite in the other group. As shown in Figure 4, the CAAR the convertible bonds with warrants is significantly positive during the event period so that it is hard to reach the conclusion that if there is a negative effect of the announcement of the convertible bonds with warrants. The values of the rate of the abnormal return are continuously positive in the time window $(-20,-10)$, but they are not significant on a certain statistics level except the value of Day -20 . But the values are negative since Day +3 .

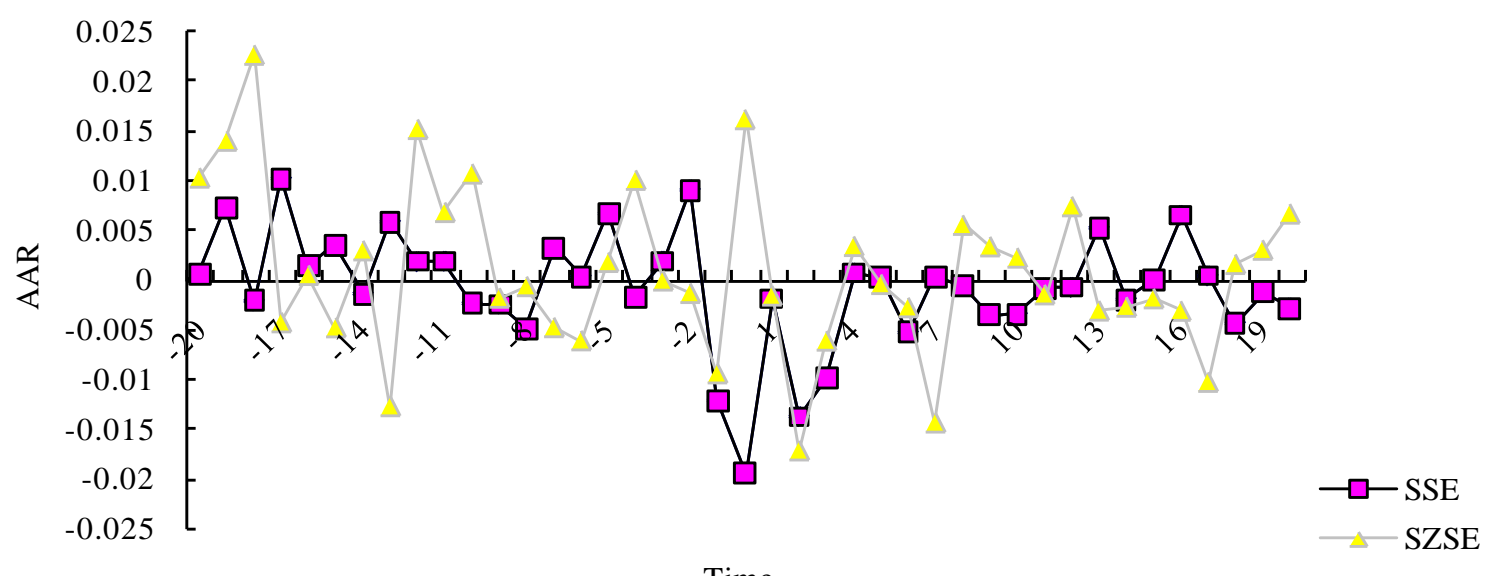

Time 


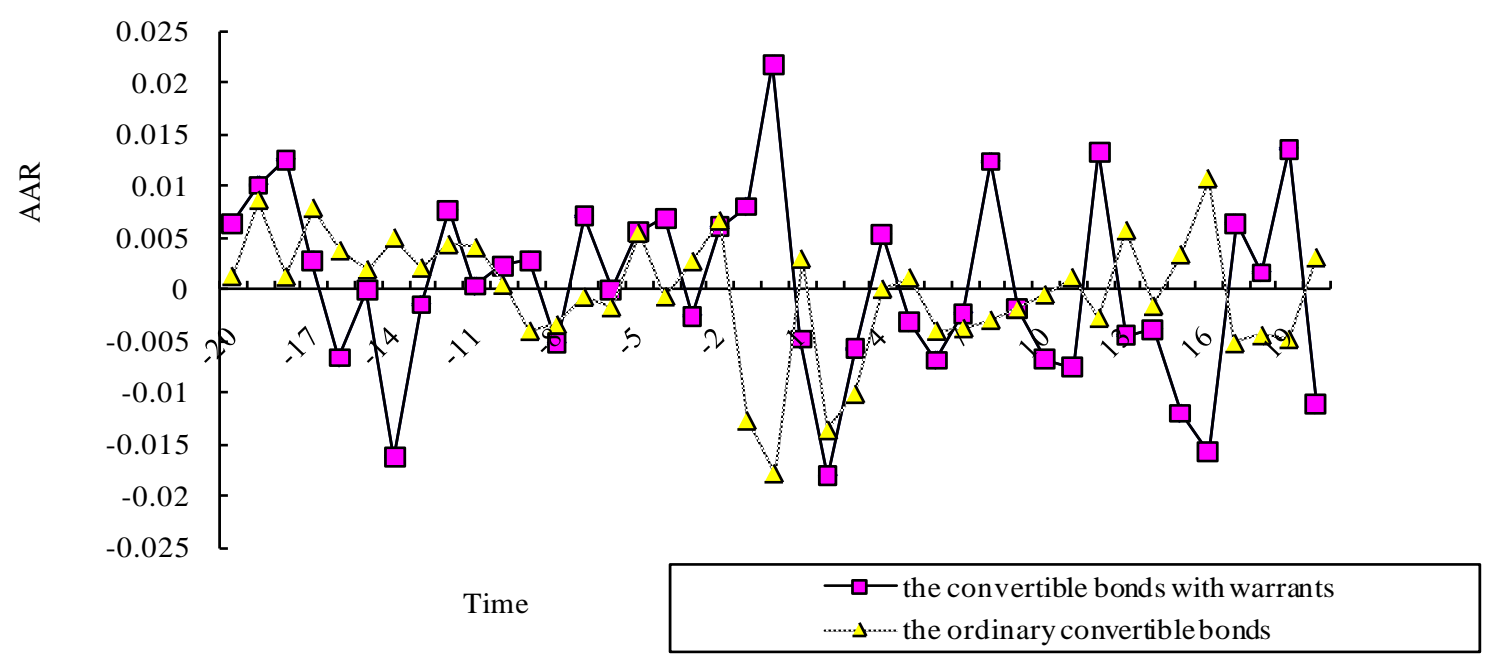

Figure 3. AAR of two convertible bonds.

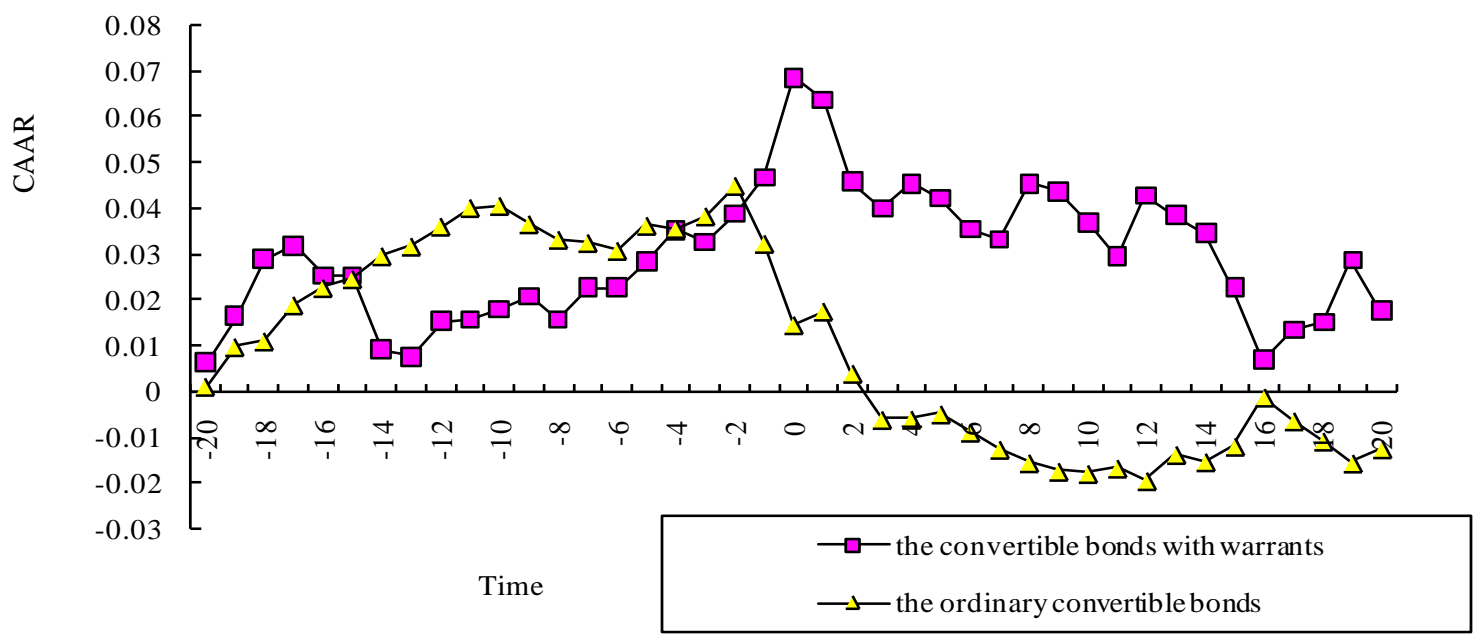

Figure 4. CAAR of two convertible bonds.

After further analysis, we can find that the result gotten by studying the samples of the ordinary convertible bonds is the same to the one of studying the all the samples. In other words, there are significantly negative effects while issuing the convertible bonds in the short term.

The announcement effect of convertible bonds with warrants is not significant. We can analyze as follows. First, it is obvious to invest in convertible bonds with warrants, the investor can both gain from the principal and interest, and buy stocks with price below the price in positive stock market, or transfer the warrants in the secondary market arbitrage for gain. That improve the inadequacies of ordinary convertible bonds, and help cautious investors to earn higher returns in a low-risk way. The gradual development of the financial derivatives market will bring new space for convertible bonds with warrants. Second, the convertible bonds with warrants passed relatively clear and positive enterprises' information that the level of performance need to be enhance. In addition, the innovation of convertible bonds with warrants impresses investors as a fresh thing to make them to have a certain impulse to invest. Then, the number of investor gets more and more, which leads the announcement effect to be not significant and positive.

\section{Conclusions and Policy Recommendations}

\subsection{Conclusions}

The paper takes data of the listed companies that have issued convertible bonds from China's A-share market as 
sample data. And the data are from 2007 to 2011. The overall research and group study are carried out by event study research. And some conclusions can be reached, as follows:

a) The announcement effect of issuance of the convertible bonds is negative. Especially in the Day 0, the significant negative abnormal return is $-1.87 \%$, lower than the U.S.

b) The study on the issuance of convertible bonds in SSE and SZSE shows that the Shanghai is more mature than Shenzhen, and the volatility of stock price is smaller. In addition, the negative announcement effect of issuance of the convertible bonds in SSE is more significant than in SZSE.

c) The study on ordinary convertible bonds and convertible bonds with warrants by grouping shows that the announcement effect of issuance of ordinary convertible bonds is more significant than the convertible bonds with warrants.

Similar to the Western countries, including the United States and Britain, the announcement effect of issuance of convertible bonds in China is negative, and the market value of companies that have issue convertible bonds is negatively impacted. The action of issuing convertible bonds of domestic companies conveys a negative message to the market, which leads the information asymmetry investors to make adverse selection. Then, the companies’ stock prices decline, and the companies' market expected values are reduced.

\subsection{Policy Recommendations}

In this paper, some relevant recommendations may be supplied for government and regulatory authorities, the issuing company and investors.

Government and regulatory authorities, firstly, need to encourage some financing enterprises to develop some new appropriate and practical varieties of convertible bonds to enrich China's financial market; Secondly, distinguish the form of issuing convertible bonds and the approval process, and develop more detailed examinations and approvals for different categories of convertible bonds; Thirdly, dynamically regulate the information disclosure authenticity of the listed companies to eliminate the occurrence of false fraud; Fourthly, increase the size of issuing convertible bonds in the domestic market of the investment entities of funds and brokerage and so on, and develop the specialized fund projects for convertible bonds; Finally, change the ideas of enacting laws and regulations, and analyze and get the nature of convertible bonds.

The main body of the issuing company needs to choose the right way at the right time to issue convertible bonds, including reasonable designing and issuing program and the correct choice of investment opportunity. Although the announcement effects of issuing the convertible bonds are negative, timely adjusting the designed program will affect the direction of the effects, then, the positive effect can be achieved. First of all, the issuing company should predict future market trends as well as investors' preference of the target market yields to rationally design the coupon rate of convertible bonds; Secondly, it should fully consider the reasonable standards of prices going up to ensure transfer stock price floating in the range of established standards. The best investment opportunity needs to be during the stock market changing from the poor to better, that can avoid more difficult to achieve conversion and raise capital.

The rational investors need to analyze the financial condition of the issuing companies in detail and interpret the issuing terms seriously. At the same time, they must always pay attention to the changes of the stock price and the interest rate so that they can be able to change the convertible bonds into the stock at the right time and obtain a higher income. In addition, the investors also pay attention to the relevant documents of the regulators and the propaganda department in order to change the investment plans according to the documents. And they can concern about the situations of the developed foreign securities markets to reference the advanced experience. And they must alter the speculative attitudes and behaviors that they sell the stocks after the conversion, because these behaviors may affect the growth of China's securities market adversely.

\section{Acknowledgements}

The completion of this paper got a lot of the teacher's help, the efforts of the classmate, with the support of the school. Therefore, thank all the people who provide advice and help.

\section{References}

[1] Dann, L.Y. and Mikkelson, W.H. (1984) Convertible Debt Issuance, Capital Structure Change and Financing Related Information: Some New Evidence. Journal of Financial Economics, 13, 157-186. 
[2] Kang, J.K. and Stulz, R.M. (1996) How Different Is Japanese Corporate Finance? An Investigation of the Information Content of New Security Issues. Review of Financial Studies, 9, 109-139.

[3] De Roon, F. and Veld, C. (1998) Announcement Effects of Convertible Bond Loans and Warrant-Bond Loans: An Empirical Analysis for the Dutch Market. Journal of Banking \& Financing, 22, 1481-1506. http://dx.doi.org/10.1016/S0378-4266(98)00055-7

[4] Guo, X.W. (2001) The Effect of Convertible Bonds on the Company's Stock Price and Its Empirical Research. (in Chinese)

[5] Wang, H.Y. and Xia, Y.P. (2004) An Empirical Study on the Effect of the Issuance of Convertible Bonds on the Company's Stock Price. Central South University for Nationalities (Natural Science Edition), 2, 106-109. (in Chinese)

[6] Wang, Y.X. and Yang, J. (2011) The Analysis of Effect of the Issuance of Convertible Bonds on the Underlying Stock. Business Culture, 3, 177-178. (in Chinese)

[7] Tian, K. and Lao, L.J. (2004) A Study on the Wealth Effect of Convertible Bonds Issued by Listed Companies in China. Shanghai Management Science, 6, 8-10. (in Chinese) 